\title{
Mobile Health Technology Adoption across Generations: Narrowing the Digital Divide.
}

Grace Fox, Irish Centre for Cloud Computing and Commerce, Dublin City University Business School, Dublin, Ireland

Regina Connolly, Dublin City University Business School, Dublin, Ireland.

\begin{abstract}
Mobile health (m-health) technologies offer many benefits to individuals, organizations, and health professionals alike. Indeed, the utilization of m-health by older adults can foster the development of proactive patients, while also reducing financial burden and resource pressures on health systems. However, the potentially transformative influence of m-health is limited as many older adults resist adoption leading to the emergence of an age-based digital divide. This study leverages protection motivation theory and social cognitive theory to explore the factors driving resistance among older adults. This mixed methods study integrates survey findings with insights from qualitative interviews to highlight that the m-health digital divide is deepening due to older adults' perceived inability to adopt, and their unwillingness to adopt stemming from mistrust, high risk perceptions, and strong desire for privacy. The paper contributes to the privacy and social inclusion literature by demonstrating that while many older adults have access to m-health, they are currently excluded, and require careful consideration by technology organizations and researchers. The study provides recommendations for narrowing the $\mathrm{m}$-health digital divide through inclusive design and educational efforts to improve self-efficacy, develop privacy literacy, and build trust, thereby ensuring older citizens are both capable, and willing to adopt.
\end{abstract}

Keywords: mobile health, digital divide, health information privacy concerns, older citizens, mobile health adoption, mixed methods, social inclusion 


\section{Introduction}

Recent technological advances which enhance data collection and analysis capabilities represent both opportunities for improving decision making and risks to individuals' privacy (Bélanger and $\mathrm{Xu}, 2015$ ). Indeed, increased data collection triggers a decrease in individuals' control over their information privacy (Conger, Pratt, and Loch, 2013). The established body of privacy literature demonstrates the inhibiting influence of privacy concerns on individuals' willingness to disclose information and adopt technologies (Bélanger and Crossler, 2011; Li, 2011; Smith, Dinev, and Xu, 2011). However, there is a need to build on this work to understand privacy in the context of emerging technologies (Martin and Murphy, 2017; Conger et al., 2013).

This study focuses on mobile health (m-health) technologies and the role of privacy in forging an m-health digital divide. Broadly described as the utilization of mobile technologies to realize health objectives, m-health encompasses a variety of mobile applications, wearable devices, and health record systems. Whilst these technologies can be leveraged by almost all individuals with Internet access, older citizens stand to benefit more from m-health usage to manage chronic conditions (Eng and Lee, 2013). However, the realization of such benefits is predicated on adoption, which remains low among older citizens (Bidmon et al., 2014, PEW, 2013), pointing to the existence of an age-based digital divide in $\mathrm{m}$-health adoption. The digital divide has been studied from a number of perspectives in the IS discipline, particularly within the social inclusion literature (e.g Windeler and Riemenschneider, 2016; Kvansy and Trauth 2002), which has focused on understanding the differences in access to technology and the technology-related opportunities afforded to individuals based on demographic characteristics such as gender and ethnicity. This important body of work has highlighted discrepancies in access to technology as well as imbalances in how technology is supported among minority groups (Windeler and Riemenschneider, 2016). In the health context, a recent study explored the influence of ethnicity, education and income on diabetics' motivation and ability to search online for health information (Morgan and Trauth, 2013). While all individuals with smartphones or devices have access to m-health, adoption among older adults remains low. Empirical examinations of the factors influencing m-health adoption remain scarce (Rai et al., 2013), with the reasons behind older adults' resistance rarely explored. As a result, the causal reasons for the age-based adoption divide remain unclear and thus call for investigation.

Concerns regarding health data privacy have been identified as a barrier facing mhealth adoption (Mosa et al., 2013; Whittaker, 2012). Furthermore, studies in 
othercontexts have shown that older citizens express higher privacy concerns (e.g. Joinson et al., 2010), exhibit an unwillingness to disclose personal information online (Goldfarb and Tucker, 2012), and resist adopting new technologies (Niehaves and Plattfaut, 2013). Consequently, it has been posited that older citizens may be less capable of adopting m-health, or less willing to adopt due to privacy concerns and low trust beliefs (Fischer et al., 2014; Or et al., 2011). The aim of this paper is twofold. First, it explores the presence of a digital divide in m-health adoption based on older citizens' perceived ability to adopt. Second, it explores their willingness to adopt, and the factors impacting this willingness.

The study builds on prior privacy research to examine the role of privacy in the context of emerging health technologies (Conger et al., 2013), and moves beyond the focus on technology adoption models by utilizing protection motivation theory to conduct a granular examination of the influence of privacy concerns, trust and risk beliefs on older citizens' m-health adoption. The paper also departs from the legacy of single method quantitative studies within privacy research (Bélanger and $\mathrm{Xu}, 2015$ ), and uses a two-stage sequential mixed methods design to develop deep insights into $\mathrm{m}$-health adoption among this group from a cross-national perspective (Martin and Murphy, 2017). Thus, the paper contributes to privacy and social inclusion literature in the health context (Xu and Bélanger, 2013), among an older adult cohort (Li et al., 2014), while also deepening understanding of adoption beyond a binary decision by elucidating the reasons why individuals do not adopt, conditions imposed on future adoption, and making recommendations to narrow the digital divide.

The paper proceeds by introducing the study context. Existing literature is then reviewed to develop the research model. The methodology applied is described prior to outlining the quantitative results, qualitative findings, and data integration. The paper concludes with the discussion, recommendations, and avenues for future research.

\section{Study Context: 'Older Adults'}

"Aging is an extraordinary process where you become the person you always should have been"

- David Bowie

Despite calls for privacy and technology adoption studies focused on older samples ( $\mathrm{Li}$ et al., 2014), this group remains under-researched. Furthermore, among the few existing studies, which either examine older adults' health technology adoption intentions or privacy concerns independently, there exists no commonality in the age range utilized or the rationale for this choice. Indeed, difficulties in defining older adults persist beyond privacy and indeed IS. The retirement age of 60 or 65 is often 
used despite variations across countries and its arbitrary treatment of the term 'older adult' (WHO, 2013). Furthermore, 'old age' is also often associated with negative connotations such as the inability to be an active participant in society (Gorman, 1999). As a consequence, definitions of age are becoming increasingly multifaceted, incorporating many characteristics including health (WHO, 2013).

This study departs from the negative connotations associated with the term 'older adults' and focuses on individuals who in chronological terms are older, and possess two important characteristics; (1) they are unlikely to currently utilize m-health but (2) could benefit from m-health. Firstly, U.S. adults aged 50+ are significantly less likely to search online for health information or utilize m-health applications (PEW, 2013). Secondly, older adults can benefit from m-health for many reasons. As the incidence of chronic illness increases with age (Nolan and Kenny, 2014), m-health can aid in health management (Eng and Lee, 2013). To accommodate the world's aging population, governments are pursing healthy aging strategies (WHO, 2015) and mhealth can empower older individuals to engage in behaviors synonymous with healthy aging (Eng and Lee, 2013). An associated economic consequence is that $\mathrm{m}$-health adoption by older citizens reduces emergency department visits by $70 \%$ and hospital stays by $80 \%$ (PWC, 2013). M-health can provide additional benefits including removing geographic barriers to health information, facilitating access to customised information, and removing the stigmatization often associated with other medical devices (Connelly et al., 2006; Cummings, Chau, and Turner, 2009; Whittaker, 2012).

In this study, the term 'older adults' represents citizens who can benefit from the assimilation of m-health technologies in their lives, but lack either the ability or the willingness to adopt (Niehaves and Plattfaut, 2013). While this cohort is defined by these characteristics, chronological age remains important to ascertain whether an mhealth digital divide exists among older adults. The age threshold is placed at 50+, as this (1) encompasses individuals from the Baby Boomer generation, (2) is frequently employed by research centers Statistica and PEW, and (3) prior studies have found that individuals in this age range limit their technology usage (CSO 2015, 2016, EIR 2015) and resist m-health utilization (PEW, 2013).

\section{Literature Review}

\section{Information Privacy}

In the IS literature, there exists copious privacy conceptualizations, the large majority of which place strong emphasis on the issue of control (Dinev et al., 2012). For instance, Bélanger and Crossler (2011) built on the assertions of Clarke (1999) to define 
privacy as individuals' desire to have greater control over the collection and dissemination of their information. The focus here is on some control as individuals maintain a desire for control (Conger et al., 2013), but many accept complete control is unobtainable in today's technology-driven world. Conversely, the Health Informatics (HI) domain is characterized by an absence of discipline-specific definitions, with many studies failing to provide any definition, whilst others integrate disparate concepts such as security and confidentiality within the definitions offered (Shaw et al., 2011). Therefore, in line with Bélanger and Crossler (2011), privacy is described as citizens' desire for a degree of control over the collection and dissemination of their health information by health organizations and technology vendors.

The complexity of the privacy concept necessitates the use of proxies, with the majority of studies harnessing privacy concerns as a proxy (Bélanger and Crossler, 2011). In the health context, such concerns are frequently measured across one dimension (e.g. Kordzadeh et al., 2016; Bansal et al., 2010; Laric et al., 2009). While this approach provides insights into the general relevance of privacy, given the nascence of $m$-health technologies it argued that a comprehensive approach is needed to identify the pertinent concerns in this context. Moreover, privacy concern has been shown to be multidimensional and is thus best measured as such (Hong and Thong, 2013). The fourdimensional 'Concern for Information Privacy' (CFIP) scale (Smith et al., 1996) has been adapted to measure citizens' health information privacy concerns (e.g. Dinev et al., 2016; Li and Slee, 2014; Hwang et al., 2012; Angst and Agarwal, 2009). These studies capture concerns across the dimensions of Collection, Unauthorized Secondary Usage, Improper Access, and Errors. However, calls have been made (Kordzadeh et al., 2016) for the consideration of Control and Awareness in the health context based on the Internet Users' Information Privacy Concerns (IUIPC) scale (Malhotra et al., 2004). In 2013, Hong and Thong combined CFIP with IUIPC to produce the sixdimensional 'Internet Privacy Concerns' (IPC) measure. To gain a comprehensive understanding of citizens' health information privacy concerns, we adapt IPC, terming it the HIPC measure. Table 1 describes each dimension of HIPC. 


\begin{tabular}{|c|c|c|}
\hline & Original & HIPC Definition \\
\hline Collection & $\begin{array}{l}\text { Concern that organizations collect } \\
\text { and store a great deal of their } \\
\text { information*. }\end{array}$ & $\begin{array}{l}\text { Concern regarding the } \\
\text { collection and storage of large } \\
\text { quantities of health data. }\end{array}$ \\
\hline $\begin{array}{l}\text { Unauthorized } \\
\text { Secondary } \\
\text { Use }\end{array}$ & $\begin{array}{l}\text { Concern that data is collected for one } \\
\text { purpose and used for a secondary } \\
\text { purpose(s) without permission*. }\end{array}$ & $\begin{array}{l}\text { Concern that health } \\
\text { information collected for one } \\
\text { purpose, is used for another } \\
\text { without permission. }\end{array}$ \\
\hline $\begin{array}{l}\text { Improper } \\
\text { Access }\end{array}$ & $\begin{array}{l}\text { Concern that organizations do not } \\
\text { have the measures in place to protect } \\
\text { against unauthorized individuals } \\
\text { accessing personal information* }\end{array}$ & $\begin{array}{l}\text { Concern that unauthorized } \\
\text { individuals might access } \\
\text { personal health data. }\end{array}$ \\
\hline Errors & $\begin{array}{l}\text { Concern that organizations do not } \\
\text { have the measures in place to prevent } \\
\text { errors in personal data*. }\end{array}$ & $\begin{array}{l}\text { Concern that organizations do } \\
\text { not have the measures in } \\
\text { place to prevent and correct } \\
\text { errors in health data. }\end{array}$ \\
\hline Control & $\begin{array}{l}\text { Concern regarding a lack of control } \\
\text { over their data**. }\end{array}$ & $\begin{array}{l}\text { Concern that one cannot } \\
\text { exercise control over their } \\
\text { personal health data. }\end{array}$ \\
\hline Awareness & $\begin{array}{l}\text { Concern regarding a lack of } \\
\text { awareness of how organizations use } \\
\text { and protect the privacy of personal } \\
\text { information }{ }^{* *} \text {. }\end{array}$ & $\begin{array}{l}\text { Concern over a lack of } \\
\text { awareness of how health data } \\
\text { is used and protected. }\end{array}$ \\
\hline
\end{tabular}

Table 1. HIPC Dimensions. * denotes Smith et al. (1996), ** denotes Malhotra et al. (2004)

\section{Technology Adoption and Mobile Health}

The majority of health technology adoption studies leverage technology adoption theories such as the Technology Adoption Model (Davis et al., 1989) or Unified Theory of Technology Acceptance and Use (Venkatesh et al., 2003). These models have provided insights into the factors influencing individuals' adoption of Internet patientphysician portals (Klein, 2007) and information based m-health applications (Lim et al., 2011). However, mixed support is provided for some technology adoption constructs such as social influence and effort expectancy (Or et al., 2011). This suggests that technology adoption models may not capture all factors influencing health technology adoption decisions and highlights the need to explore additional factors. In parallel with repeated calls to examine the influence of privacy on m-health adoption (Wu et al., 2007), privacy concerns have been positioned as a barrier to m-health adoption among older adults (Sun et al., 2013; Guo et al., 2013; Fischer et al., 2014). This study moves beyond the reliance on technology adoption to explore the influence of privacy on older individuals' willingness to adopt m-health.

In addition to privacy concerns, risk and trust beliefs represent important factors in privacy research. Trust has attracted attention in the electronic commerce context as 
technology replaces face-to-face interactions between citizens and organizations (Keith et al., 2015). Similarly, m-health technologies replace face-to-face interactions between citizens and health professionals, whilst facilitating the disclosure of health data to technology organizations via m-health applications. It is thus argued that trust in these organizations is imperative. The literature shows that greater the level of trust the individual has in the benevolence (belief that the trustee acts in the individual's best interest) and integrity (belief that the trustee is honest), the lower the manifestation of privacy concerns (McKnight et al., 2002). In the health context, the existing literature provides some support for the influence of trust. For example, trust in EHR vendors reduces HIPC (Dinev et al., 2016), and trust in health websites increases willingness to interact with websites (Bansal et al., 2010). To our knowledge, no study has explored the influence of trust on older citizens' m-health adoption. As trust is often positioned as a core consideration among this group (Or et al., 2011), it is imperative to investigate the role of trust in the m-health context. Risk beliefs refer to an individual's expectation that disclosing health information will result in a negative outcome (Dinev et al., 2012). Risk beliefs are often studied as the antithesis of trust. Despite research showing that risk beliefs increase privacy concerns towards health websites (Xu et al., 2011) and reduce intentions to adopt wearable health devices ( $\mathrm{Li}$ et al., 2016), the influence of risk beliefs among an older sample remains undetermined and requires exploration.

\section{Model Development}

Several theories have been extended to examine privacy in the IS literature (Li, 2012). In contrast, many HI studies lack theoretical foundations (Or and Karsh, 2009). As the sensitive nature of health data necessitates the adaptation of existing theories (Agarwal et al., 2010), this study leverages social cognitive theory (SCT) and protection motivation theory (PMT) to explore older citizens' ability and willingness to adopt. Developed by Bandura (1977), social cognitive theory emphasizes the importance of self-efficacy or an individual's perception of their ability to perform a certain behavior. Self-efficacy has been adapted in various disciplines, such as technology adoption where computer self-efficacy is positioned as a predictor of adoption (Compeau and Higgins, 1995). Within the privacy literature, Keith et al. (2015) developed mobile computing self-efficacy (MCSE) to explore its influence on information disclosure. In this study, we focus on m-health self-efficacy or individuals' perceived ability to utilize m-health to manage their health.

PMT was developed to explore the influence of threat and coping appraisals on health behaviors (Rogers, 1975). Components of PMT have been harnessed in privacy studies 
in contexts other than health, as the theory provides a flexible lens for exploring the competing impacts of threat and coping appraisals ( $\mathrm{Li}, 2012)$. Threat appraisal relates to individuals' perceptions of the breadth of threats facing their information, the severity of threats, and the likelihood these threats will occur. Coping appraisal relates to individuals' perception of their ability to engage in behaviors which diminish these threats. In this study, the breadth and severity of the threats facing health data are represented by HIPC. Risk beliefs relate to individuals' perception of the likelihood that the perceived threats (HIPC) will occur.

Coping appraisal is represented by individuals' trust in m-health vendors. Trust beliefs may reduce the negative impacts of HIPC and risk beliefs, as if individuals trust the technology vendor, they believe they are less likely to engage in negative behaviors or the threats they perceive. In other words, trust can alleviate many of the fears and concerns individuals have when disclosing their health data in m-health solutions. As illustrated in Figure 1, we propose that older citizens' m-health adoption intentions are influenced by their perceived ability to adopt, their cognitive assessment of the threats these technologies present and their ability to cope with these threats.

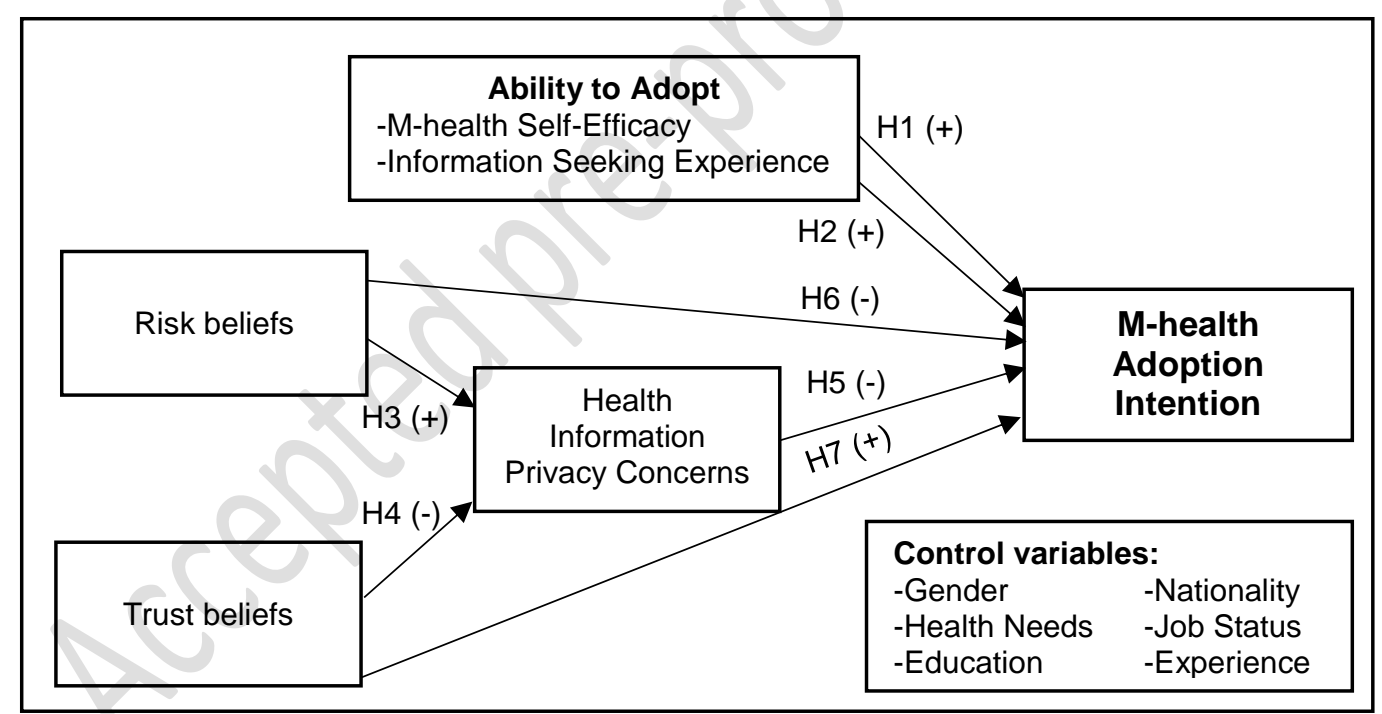

Figure 1. Proposed Model

\section{Hypotheses}

The practice of seeking health information online is becoming increasingly popular. However, while $72 \%$ of American adults engage in this practice, only $54 \%$ of adults aged 50-64 do so (PEW, 2013). Online health information seeking experience can positively influence m-health intentions among younger individuals (Lim et al., 2011; Bidmon et al., 2014). As prior experience is likely to suggest a comfort using technology for health purposes, we examine this relationship among older adults. 
H1. Online health information seeking behavior is positively associated with $\mathrm{m}$-health adoption intentions.

Self-efficacy defined as 'a judgement of one's ability to execute a particular behavior'(Bandura, 1977 p.240), has been shown to indirectly influence intentions towards web-based self-management health systems and m-health via performance expectancy (Or et al., 2011; Kim and Park, 2012). In addition, Sun et al. (2013) found that self-efficacy influenced $\mathrm{m}$-health service adoption intentions among older adults in China. In this study, we explore the influence of specific m-health self-efficacy.

H2. M-health self-efficacy is positively associated with m-health adoption intentions.

Research shows that risk beliefs increase privacy concerns towards health websites $\mathrm{Xu}$ et al., 2011). Moreover, researchers discussing the many privacy risks generated by health ICTs argue that individuals' perceptions of these risks are likely to exacerbate their HIPC (Fichman et al., 2011). This relationship has not been explored among older adults, but it is proposed that if older adults perceive health technologies involve high risk; they will express higher HIPC.

H3. Risk beliefs are positively associated with HIPC.

The emergence of m-health solutions leaves many unanswered questions surrounding the role of trust. Trust in EHR vendors has been found to reduce HIPC among U.S. and Italian citizens (Dinev et al., 2016). This paper explores how older adults' trust in mhealth technology vendors influences their HIPC.

H4. Trust beliefs are negatively associated with HIPC.

Previous research shows that privacy concerns reduce individuals' willingness to adopt EHRs and Personal Health Records (Angst and Agarwal, 2009; Li and Slee, 2014). This study builds upon prior work to explore the influence of HIPC on m-health adoption among older adults, as privacy concerns have been found to represent a barrier to usage among this group (Fischer et al., 2014).

H5. HIPC are negatively associated with m-health adoption intentions.

Prior research also shows that risk beliefs reduce individuals' intentions and use of wearable health devices ( $\mathrm{Li}$ et al., 2016). This paper explores the influence of risk beliefs on $\mathrm{m}$-health adoption among older adults.

H6. Risk beliefs are negatively associated with $\mathrm{m}$-health adoption intentions. 
The role of trust remains unclear in the health context and indeed in the privacy context (Kehr et al., 2015). However, a recent study found that trust in health websites increased willingness to use these websites (Bansal et al., 2010). It is thus proposed that individuals who express high trust beliefs regarding m-health technology vendors are more likely to adopt m-health.

H7. Trust beliefs are positively associated with m-health adoption intentions.

\section{Methodology}

There is a paucity of mixed methods studies in IS, leading to calls to employ mixed methods to develop meaningful insights into complex IS problems (Venkatesh, Brown, and Bala, 2013). This paper utilizes a mixed methods design underpinned by the pragmatic philosophical paradigm. Combining the ontological positions of postpositivism and constructivism, pragmatism is a practical, flexible and applied research philosophy which advocates action over philosophy (Teddlie and Tashakkori, 2009). As mixed methods studies are often critiqued for inadequate explanations of the research (Venkatesh et al., 2013), this study follows GRAMMS (Good Reporting of a Mixed Methods Study) and discusses the (1) study aims, (2) research design (3) data collection procedures (O'Cathain et al., 2008). The study aim aligns with the application of mixed methods to develop a multi-perspective understanding of privacy concerns and $\mathrm{m}$-health adoption among older citizens. Following the practical nature of pragmatism, the most appropriate methods for meeting this aim were chosen (Greene and Caracelli, 2003), which included a quantitative survey to test the relationships and in-depth interviews to explain these relationships. Data collection was sequential and weighted as follows: Quan $\rightarrow$ Qual. This approach is explanatory (Creswell and Plano Clark, 2007), with qualitative data utilized to explain quantitative findings.

\section{Data Collection and Survey Development}

This study focused on citizens in the United States and Ireland. The majority of privacy research utilizes U.S. samples, leading to calls for European studies (Bélanger and Crossler, 2011). Collecting data from these two countries also strengthens the extension of constructs to the health context. Prior to data collection, ethical approval was granted from both Universities (Dublin, Ireland and Southwest, USA). Purposive sampling was followed for quantitative and qualitative data collection to ensure citizens of varying age, health status, technological competence, and education were included (Kemper et 
al., 2003). Survey responses from older adults were gathered using two methods ${ }^{1}$ including (1) email invitations sent to participants in previous research who indicated their willingness to partake in future studies and (2) visiting exercise and technologybased programmes at the Universities to introduce the study and request participation. Survey participants volunteered contact information if they were willing to participate in interviews. These volunteers were screened in accordance with the sample criteria and 17 interviews were conducted with participants aged 50+.

Survey constructs were developed from validated measures. Health information seeking (INF) and m-health self-efficacy (MHSE) were measured using 4 and 5 items based on Kim and Park (2012). Trust beliefs (TRT) and risk beliefs (RSK) were drawn from Li et al. (2014), and Hong and Thong (2013), and consisted of 6 and 4 items. HIPC was measured using 19 items across six dimensions from Hong and Thong (2013). Intention to adopt (INT) was examined using 3 items from Venkatesh et al. (2003). Control variables included gender, nationality, education, job status, and healthcare need (Wilson and Lankton, 2004). In line with Keith et al. (2015), control variables pertinent to self-efficacy were included, namely internet and $\mathrm{m}$-health experience. As many items were reworded to the health context, pilot testing was required. Academic experts provided advice on rewording items and descriptions. The survey was piloted on 10 Irish citizens of varying ages who provided feedback on question and instruction clarity. An interview guide was developed with introductory, follow-up, and specifying questions for each construct (Kvale, 1996). This was piloted among academics and citizens to ensure each question was unambiguous.

\section{Reliability and Validity}

Recommended guidelines were followed to determine the reliability and validity of the data (Venkatesh et al., 2013). Qualitative validity was achieved across three categories: design, analytical, and inferential validity. To achieve design validity across descriptive validity, credibility, and transferability, procedures included using probing questions for comprehensiveness, replaying tapes for tone and emphasis, and conducting informal member checks (Lincoln and Guba, 1985). Analytical validity which includes theoretical validity, dependability and consistency was achieved by leveraging existing theory and integrating data to improve dependability. To achieve inference validity and confirmability, methods included using multiple methods, thick descriptions, and

\footnotetext{
${ }^{1}$ Participants aged 18-49 were recruited using email invitations sent to Undergraduates, Postgraduates and Alumni from both Universities (located in Dublin, Ireland and Southwest, USA), as well as non-faculty staff and individuals who had partaken in previous research and indicated their willingness to participate in future research.
} 
member checking. Several member checking approaches were used including asking participants to elaborate on views expressed, summarizing statements and seeking agreement clarification throughout and at the end of each interview. In a small number of cases, interviewees were contacted via phone to elaborate on a statement. Integrated quantitative and qualitative data must meet three validity criteria: integrative efficacy, integrative correspondence, and inference transferability (Venkatesh et al., 2013). Integrative efficacy was achieved using a triangulation protocol to consistently weave findings and produce a multi-perspective understanding of each relationship (Teddlie and Tashakkori, 2009). Integrative correspondence requires that the findings satisfy the aims. To ensure the study's aim was met, the relationships were quantitatively examined, explained using qualitative data, and integrated. Inference transferability refers to the degree to which inferences can be transferred. Inferences are pertinent to older citizens in two countries, and can be extended in further research.

\section{Quantitative Analysis}

The complete sample consisted of 447 responses (247 Ireland, 202 U.S). This sample was used to test the psychometric properties of the instrument. A total of 125 (28\%) respondents were aged 50+. The characteristics of this sample are detailed in Table 2.

\begin{tabular}{|c|c|c|c|}
\hline & Category & $\mathrm{N}=125$ & $\%$ \\
\hline \multirow[t]{2}{*}{ Gender } & 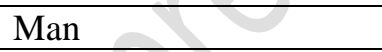 & 65 & $52.0 \%$ \\
\hline & Woman & 60 & $48.0 \%$ \\
\hline \multirow[t]{5}{*}{ Age } & $50-54$ & 23 & $18.4 \%$ \\
\hline & $50-59$ & 30 & $24.0 \%$ \\
\hline & $60-64$ & 16 & $12.8 \%$ \\
\hline & $65-69$ & 26 & $20.8 \%$ \\
\hline & $70+$ & 30 & $24.0 \%$ \\
\hline \multirow[t]{4}{*}{ Education } & Secondary Level & 44 & $35.2 \%$ \\
\hline & Some College & 25 & $20.0 \%$ \\
\hline & Undergraduate degree & 31 & $24.8 \%$ \\
\hline & Postgraduate degree & 25 & $20.0 \%$ \\
\hline \multirow[t]{3}{*}{ Employment status } & Other & 12 & $9.6 \%$ \\
\hline & Employee & 47 & $37.6 \%$ \\
\hline & Retired & 66 & $52.8 \%$ \\
\hline \multirow[t]{5}{*}{ Internet Experience } & None & 4 & $3.2 \%$ \\
\hline & $<5$ years & 22 & $17.6 \%$ \\
\hline & 5-10 years & 28 & $22.4 \%$ \\
\hline & $10-15$ years & 20 & $16.0 \%$ \\
\hline & $15+$ years & 51 & $40.8 \%$ \\
\hline \multirow[t]{3}{*}{ Chronic Illness } & Yes & 58 & $46.4 \%$ \\
\hline & No & 67 & $53.6 \%$ \\
\hline & Unsure & 28 & $6.2 \%$ \\
\hline \multirow[t]{2}{*}{ Sensitive Illness } & Yes & 22 & $17.6 \%$ \\
\hline & No & 103 & $82.4 \%$ \\
\hline
\end{tabular}

Table 2. Sample Characteristics. 


\section{Measurement Model}

Quantitative analyses consisted of a number of phases. First, the data were cleaned and screened to ensure the assumptions of multivariate analysis were met (Hair et al., 2010). The second phase involved using the full sample $(n=447)$ to test the proposed factor structure and validate all adapted constructs including the $2^{\text {nd }}$ order privacy concerns (HIPC) scale. Using the full sample was important to determine construct validity and reliability in the m-health context and to conduct invariance testing amongst the different groups. The factor structure for all constructs was tested among the complete sample using Confirmatory Factor Analysis (CFA) in AMOS 24. Several items were dropped due to low loadings including MHSE1 (.484), MHSE2 (.448), INF4 (.510), and TRT5 (.575). Model fit statistics indicated good fit meeting the recommendations of Hair et al. (2010) for the sample size and number of variables. The fit statistics were: $\mathrm{cmin} / \mathrm{df}: 2.366, \mathrm{CFI}=.930, \mathrm{RMSEA}=.055, \mathrm{SRMR}=.048$. The third phase of analysis involved invariance testing to determine if the different groups within the sample interpreted constructs similarly. Invariance testing was conducted based on the different age groups and nationalities. First, multi-group comparison was conducted with both age groups using the unconstrained model. The model retained good fit, thus indicating that the groups are similar (cmin/df: 1.629 CFI: .924 RMSEA: .038, SRMR: .063). Upon constraining the regression weights across both groups, model fit statistics remained strong, further establishing configural invariance (Gaskin, 2012). Metric invariance was explored by comparing the regression weights for each relationship between the two groups. As at least one item from each construct was insignificant, partial metric invariance was achieved (MacKenzie et al., 2011). Multi-group comparisons were then conducted based on respondent nationality. Configural invariance was demonstrated through strong model fit in the unconstrained model (cmin/df: 1.737 CFI: .930 RMSEA: .041, SRMR: .046) and the constrained model. Partial metric invariance was also achieved across respondents from both countries.

The next step of analysis involved testing the validity and reliability of all constructs. Firstly, convergent validity was tested by calculating the Average Variance Extracted (AVE). As the AVE for each construct was above .50, convergent validity was achieved (Fornell and Larcker, 1981). Secondly, discriminant validity was tested by comparing the square root of the AVE and the correlation between each set of constructs (Hair et al., 2010). As shown in Table 3, (on the diagonal in bold), all variables are discriminately valid, as the square root of the AVE for each construct is greater than intercorrelation values (Gaskin, 2012). Thirdly, reliability was tested by calculating the composite reliability (CR). The CR for all constructs is above the 
recommended .70 value (Raykov, 1997). The data is therefore valid and reliable. Factor loadings for all items are presented in the Appendices.

\begin{tabular}{|l|r|r|r|r|r|r|r|r|l|}
\hline & \multicolumn{1}{l|}{ CR } & \multicolumn{1}{c|}{ AVE } & \multicolumn{1}{l|}{ INT } & \multicolumn{1}{l|}{ TRT } & \multicolumn{1}{l|}{ RSK } & HIPC & INF & MHSE & HN \\
\hline INT & 0.96 & 0.88 & $\mathbf{0 . 9 4}$ & & & & & & \\
\hline TRT & 0.90 & 0.57 & 0.18 & $\mathbf{0 . 7 6}$ & & & & & \\
\hline RSK & 0.93 & 0.75 & -0.22 & -0.52 & $\mathbf{0 . 8 7}$ & & & & \\
\hline HIPC & 0.98 & 0.89 & -0.04 & -0.29 & 0.43 & $\mathbf{0 . 9 5}$ & & & \\
\hline INF & 0.82 & 0.60 & 0.30 & 0.08 & -0.14 & -0.01 & $\mathbf{0 . 7 8}$ & & \\
\hline MHSE & 0.85 & 0.70 & 0.26 & 0.04 & 0.06 & 0.19 & 0.14 & $\mathbf{0 . 8 1}$ & \\
\hline HN & 0.82 & 0.61 & 0.03 & 0.05 & 0.01 & 0.08 & 0.04 & 0.10 & $\mathbf{0 . 7 8}$ \\
\hline
\end{tabular}

Table 3. Validity and Reliability

The examination of endogenous and exogenous variables simultaneously can generate fears regarding common method bias (CMB). Based on Podsakoff et al. (2003), procedural remedies were employed including assuring respondents there were no right or wrong answers, reducing ambiguity in scale items and randomizing items. The single common latent factor approach was used to test for $\mathrm{CMB}$ by adding a common latent factor to the CFA and comparing standardized regression weights prior to adding the factor to those post-addition of the factor (Gaskin, 2012). As none of the standardized regression weights experienced a great change (all deltas under .200), and all constructs met validity and reliability thresholds, CMB is not an issue in the data.

\section{Hypothesis Testing}

Hypotheses were tested among the sample of respondents aged 50+ $(\mathrm{N}=125)$ using AMOS 24. The structural model indicated good fit: cmin/df: 1.31, CFI: .983, RSMEA: .050, SRMR: .054. The first two hypotheses examined respondents' ability to adopt. H1 proposed that online health information seeking experience would increase intentions. This relationship was strongly supported in the data $(.328, \mathrm{p}<.001) . \mathrm{H} 2$ proposed a positive association between m-health self-efficacy and intentions. This relationship was also strongly supported $(.360, \mathrm{p}<.001)$. H3 posited that risk beliefs would positively impact HIPC, with $\mathrm{H} 4$ positing a negative relationship between trust beliefs and HIPC. The positive relationship between risk beliefs and HIPC was evidenced in the data supporting $\mathrm{H} 3(.321, \mathrm{p}<.001)$. The relationship between trust and HIPC was not significant, nor negative, rejecting H4. The remaining hypotheses explored threat and coping appraisals. H5 proposed that HIPC would reduce intentions. The data revealed a significant, negative relationship supporting H5 (-.227 p<.01). H6 proposed a negative association between risk beliefs and intentions. This relationship was not significant thereby rejecting H6. However, bootstrapping using 2000 samples was run in AMOS to explore the indirect influence of risk (Preacher and Hayes, 2004). 
The data revealed a significant indirect relationship between perceived risk and intentions in the anticipated direction $(-.073, \mathrm{p}<.01)$ indicating that HIPC indirectly mediates the relationship between risk beliefs and intentions (Zhao, Lynch and Chen, 2010). Lastly, H7 posited that trust beliefs would positively impact intentions. This relationship was supported $(.161, \mathrm{p}<.05)$. As shown in Figure 2, the findings support many of the proposed relationships and explain $45.4 \%$ of the variance in individuals' m-health adoption intentions. Individuals' ability to adopt strongly influences intentions as individuals with health information seeking experience and higher selfefficacy express higher intentions. HIPC are influenced by risk beliefs but not trust. HIPC and trust beliefs directly influence adoption intentions whereas risk beliefs indirectly influence intentions.

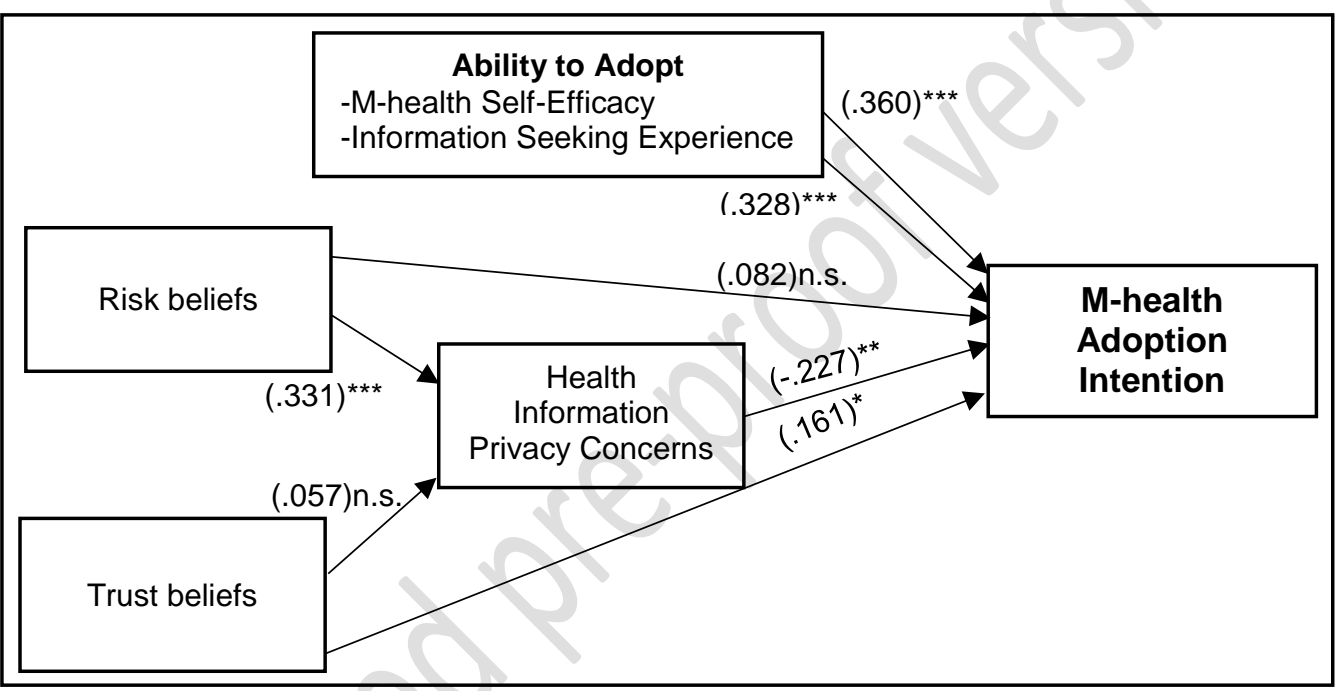

Figure 2. SEM Results * $\mathrm{p}<.05, * * \mathrm{p}<.01, * * * \mathrm{p}<.001$

\section{Qualitative Analysis}

Seventeen interviews were conducted with participants aged 50+. The characteristics of this group are outlined in Table 4. Data were analyzed using framework analysis, a deductive analysis method which is useful when constructs have been identified beforehand (Ritchie and Spencer, 1994). This section provides a brief overview of the main insights relating to each relationship and highlights pertinent insights based on age or nationality differences. Further age and nationality related insights are provided in the Appendices. 


\begin{tabular}{|r|r|l|l|l|}
\hline & \multicolumn{1}{|l|}{ Age } & Education & Job Status & Health \\
\hline 1 & 70 & Postgraduate Degree & Finance & No health problems \\
\hline 2 & 68 & Secondary School & Retired & Chronic Condition \\
\hline 3 & 55 & Postgraduate Degree & Nurse & Chronic Condition \\
\hline 4 & 68 & Undergraduate Degree & Retired & Chronic Condition \\
\hline 5 & 66 & Secondary School & Retired & No health problems \\
\hline 6 & 55 & Secondary School & Retail & No health problems \\
\hline 7 & 67 & Secondary School & Retired & Chronic Condition \\
\hline 8 & 68 & Secondary School & Retired & Chronic Condition \\
\hline 9 & 65 & Secondary School & Housekeeper & No health problems \\
\hline 10 & 52 & Postgraduate Degree & Finance & No health problems \\
\hline 11 & 65 & Postgraduate Degree & Healthcare & No health problems \\
\hline 12 & 58 & Secondary School & Retired & No health problems \\
\hline 13 & 77 & Secondary School & Retired & Chronic Condition \\
\hline 14 & 51 & Undergraduate Degree & Engineer & Chronic Condition \\
\hline 15 & 57 & Postgraduate Degree & Admin & Sensitive Condition \\
\hline 16 & 54 & Undergraduate Degree & Admin & Chronic Condition \\
\hline 17 & 56 & Undergraduate Degree & Social work & No health problems \\
\hline
\end{tabular}

Table 4. Interviewee Details

\section{Information Seeking}

Of the 17 interviewees, 14 had previously searched online for health information. Interviewees with no experience were aged between 60 and 70, thus indicating some differences in experience. The frequency of this behavior varied greatly with 6 interviewees searching infrequently for specific information when recommended by a health professional, whereas 8 interviewees searched frequently as the need arose. Those in the latter group were younger (50-60) and more experienced with technology through exposure in the workplace. Interestingly, 12 interviewees discussed limits on the type of health information they seek online, with the majority (10) willing to search for diet, fitness, and seemingly benign health issues but not for sensitive health conditions. The reasons for this included a lack of trust in information accuracy, fear of extreme diagnoses, and privacy concerns regarding unauthorized secondary usage through targeted advertising. Interviewees with greater experience expressed favourable intentions towards $\mathrm{m}$-health adoption for fitness and diet purposes.

\section{M-health Self-efficacy}

Most interviewees (15) expressed low m-health self-efficacy. Indeed, 11 interviewees were relatively unaware of $\mathrm{m}$-health technologies. This is surprising given that many interviewees have sought health information online for one purpose or another and suggests that older individuals may lack the awareness or skills required to leverage mhealth. Despite low awareness and self-efficacy at present, 10 interviewees believed that with help, they could use these technologies. The importance of self-efficacy was 
apparent as interviewees noted that they would not be comfortable using these solutions unless they 'understood what happened when they pushed the buttons' (P13, Woman, Retiree, Ireland). Interviewees expressed a desire to receive help from informal sources such as family and friends (8), and from formal channels such as courses at doctors' offices (5), community centers and Universities (9). For some interviewees (5), understanding how to use m-health solutions was not sufficient for adoption. Among this group, 3 interviewees expressed low trust levels and fear for privacy and 2 noted the importance of benefits stating 'I need to be sure it would help me' (P15, Woman, Admin Worker, USA).

\section{Risk Beliefs}

Many interviewees (14) believed disclosing health data via m-health technologies could lead to negative outcomes. Among this group, 8 discussed risk in broad terms citing potential loss of privacy, the anonymous nature of technology organizations, and the risk of inaccurate data. This group also expressed high privacy concerns in a broad sense. In addition, 6 interviewees discussed specific concerns such as unauthorized secondary use of data. The data supports the extension of PMT as when individuals believed there was a high likelihood of negative outcomes, they expressed high privacy concerns (broad and specific), and negative intentions towards using m-health for sensitive purposes or disclosing health data to technology companies with one interviewee exclaiming 'I wouldn't tell them anything, it's all about money and how they can use it' (P5, Man, Retiree, Ireland). For many individuals, abstinence was the only way to avoid negative outcomes (10). Others stated reassurance that these risks would not occur could lead to adoption.

\section{Trust Beliefs}

Several interviewees (11) expressed low trust in the integrity and benevolence of mhealth vendors due to their commercial aims. They believed that m-health vendors would utilize their data in a multitude of ways to generate profit. This belief led to heightened concerns regarding unauthorized secondary use and improper access. Some interviewees (6) expressed moderate levels of trust based on an assumption that these vendors 'would have some ethos in place' to respect data. Such assumptions illustrate the knowledge gap among some older individuals in terms of the potential uses for health data. Among the interviewees who expressed low trust, some noted that if the technology vendors could prove trustworthiness, they would consider adoption. Interestingly, interviewees who expressed high self-efficacy also demonstrated higher trust and lower risk beliefs. These interviewees aged 56 and 65 had greater experience 
seeking health data online. This experience may create a degree of comfort in using technology for health purposes and foster a sense of control thus reducing perceived risk and leading to a trust bias.

HIPC

All interviewees expressed a strong desire for health privacy and expressed specific concerns regarding unauthorized secondary use and improper access. While 12 interviewees were willing to consent to the use of their data for altruistic purposes such as medical research, interviewees were strongly opposed to use for commercial purposes especially marketing. Consent was imperative for any usage. In terms of improper access, interviewees believed data disclosed via m-health should not be shared with third parties. Interviewees also expressed a strong desire to control how data they disclosed was used. However, a surprisingly large number of interviewees (10) expressed medium concerns about their current health data privacy. For some (4), this was based on the fact they do not currently use m-health and the belief their privacy is not at risk. For others (6), the idea of using m-health technologies to track fitness was harmless and could aid in healthy ageing. The large majority of interviewees irrespective of current concern levels or age (15) expressed a strong unwillingness to utilize m-health solutions to track sensitive health conditions due to fears regarding unauthorized secondary use, improper access, and awareness. This shows that privacy represents a salient barrier to adoption among older adults.

\section{Intentions}

Some interviewees expressed a strong unwillingness to adopt m-health (5). However, many were interested provided several caveats were met. Firstly, interviewees expressed a preference for recommended reliable, m-health solutions designed for older adults. Secondly, education in effectively using these technologies is imperative. Thirdly, interviewees expect their health data to remain private and are strongly against secondary usage. Fourthly, m-health vendors should be transparent and prove their trustworthiness. Lastly, vendors should seek to reduce risk beliefs by ensuring individuals are aware and in control of their data. The type of m-health solution interviewees were willing to utilize remained limited to those related to non-sensitive data.

\section{Data Integration}

Data were integrated using a triangulation protocol, which combines findings to develop a more comprehensive picture (O'Cathain et al., 2010). Each key relationship 
was reviewed to determine if the findings from both methods were complementary (offer similar insights), convergent (enhance understanding when combined), or dissonant (offer differing views). The integrated results are outlined in Table 5.

\begin{tabular}{|c|c|c|c|}
\hline & $\begin{array}{l}\text { Quant. } \\
\text { Findings }\end{array}$ & Qual. Findings & Integration \\
\hline $\mathrm{INF} \rightarrow \mathrm{INT}$ & $\checkmark$ & $\begin{array}{l}\text { Experience seeking health data online } \\
\text { increases comfort in using m-health for } \\
\text { non-sensitive health issues. }\end{array}$ & Convergent \\
\hline $\mathrm{MHSE} \rightarrow \mathrm{INT}$ & $\checkmark$ & $\begin{array}{l}\text { Understanding and awareness of m- } \\
\text { health is currently low but imperative } \\
\text { to adoption. }\end{array}$ & Complementary \\
\hline $\mathrm{RSK} \rightarrow \mathrm{HIPC}$ & $\checkmark$ & $\begin{array}{l}\text { Risk beliefs can heighten concerns } \\
\text { regarding secondary use and improper } \\
\text { access. }\end{array}$ & Complementary \\
\hline $\mathrm{TRT} \rightarrow \mathrm{HIPC}$ & $x$ & $\begin{array}{l}\text { Low trust in m-health vendors } \\
\text { heightens concerns regarding } \\
\text { secondary use and improper access, } \\
\text { and increases desire for control and } \\
\text { awareness. }\end{array}$ & Convergent \\
\hline $\mathrm{HIPC} \rightarrow \mathrm{INT}$ & $\checkmark$ & $\begin{array}{l}\text { Older citizens express a high desire for } \\
\text { privacy, often assume privacy is } \\
\text { guaranteed but are unwilling to use m- } \\
\text { health for sensitive health issues. }\end{array}$ & Convergent \\
\hline $\mathrm{RSK} \rightarrow \mathrm{INT}$ & $\checkmark *$ & $\begin{array}{l}\text { Individuals are less willing to utilize m- } \\
\text { health if they believe it will lead to } \\
\text { negative outcomes. }\end{array}$ & Dissonance \\
\hline $\mathrm{TRT} \rightarrow \mathrm{INT}$ & & $\begin{array}{l}\text { Lack of trust decreases intentions. } \\
\text { Proving trustworthiness may increase } \\
\text { willingness to adopt }\end{array}$ & Dissonance \\
\hline
\end{tabular}

Table 5. Integrated Data. $\checkmark$ Supported, $\times$ Not Supported $\checkmark *$ Indirect Effect Observed

\section{Discussion}

Through a dual focus on social cognitive theory and protection motivation theory, this study develops a fuller picture of older individuals' ability to adopt m-health. At present, low m-health self-efficacy represents a major barrier to m-health adoption and health information disclosure among this group. This is an important finding, as mobile self-efficacy did not influence information disclosure in a prior study (Keith et al., 2015). This study extends the findings of Sun et al. (2013), confirming that self-efficacy is a barrier to m-health adoption amongst older adults in Ireland and the US. Perceived ability to use technology for a specific purpose such as health monitoring may be more salient among older citizens, or the role of self-efficacy may be heightened in this context due to the sensitivity of health data. Self-efficacy was an important influencer 
on intentions from a utilitarian perspective with interviewees highlighting the importance of comfort using all features of a new m-health technology.

In line with PMT, willingness to adopt was explored in terms of threat and coping appraisals. Beliefs regarding trust and risk (indirectly) influenced intentions and this interplay between threat and coping appraisals was also evident in the qualitative data. The data showed that HIPC, risk beliefs, and trust beliefs could each reduce m-health adoption independently, but their influence was interconnected. For instance, if individuals expressed high levels of privacy concern regarding specific dimensions and high risk beliefs, they were likely to abstain from m-health usage, irrespective of their trust beliefs. In contrast, when individuals' concerns were purely broad in nature, they often held an assumption of trust and as a result were willing to utilize m-health for non-sensitive purposes, irrespective of their risk beliefs. Furthermore, when individuals expressed a specific mistrust in m-health vendors' integrity and benevolence, specific privacy concerns and risk beliefs were heightened. In such situations, individuals were staunchly opposed to adoption. These findings indicate that the salience of HIPC, risk and trust beliefs is interconnected, dependent on the specificity of concerns and beliefs, and often influenced by engagement in privacy-protective behaviors such as withholding sensitive data (Son and Kim, 2008).

Linkage between SCT and PMT was also found in the qualitative data. Interviewees with greater online health data seeking experience expressed confidence in their ability to quickly learn to use m-health. Some of these interviewees also assumed they possessed the skills necessary to manage the threats facing their data in m-health. This echoes the assertions of Keith et al. (2015), who note that self-efficacy can manifest in false beliefs about risk and trust leading individuals to expose themselves to greater threats via mobile applications. Our findings suggest this may occur in m-health, which is more dangerous if it leads to $\mathrm{m}$-health adoption and the disclosure of sensitive health data without understanding the risks. Furthermore, interviewees with low $m$-health self-efficacy also expressed low privacy self-efficacy, that is they did not believe they possessed the ability to protect their personal information while using m-health. Thus, it is pivotal not only to arm older citizens with the skills to adopt, but to ensure they are educated on the privacy risks, implications and privacy enhancing techniques.

This study makes several contributions to privacy and social inclusion literatures. First, acknowledging the contextual nature of privacy (Nissenbaum, 2010), this study illuminates the role of privacy in the health context (Bélanger and $\mathrm{Xu}, 2015$ ). The integrated findings provide several important insights; (1) older individuals in this 
study express a strong desire for health data privacy, (2) any secondary use or access is deemed a privacy violation, (3) individuals abstain from m-health adoption to preserve their privacy or limit use to non-sensitive issues. However, individuals who lack privacy literacy often assume their health data will only be accessed when they use an m-health application. Research into the practices of m-health application vendors (FTC, 2014) suggest these assumptions are flawed. Due to the sensitivity of health data, we urge privacy researchers to further investigate the gaps in privacy knowledge (Crossler and Bélanger 2017) across all age groups and privacy contexts to inform educational efforts which can build literacy and address knowledge gaps.

Second, the study leverages SCT to enhance our understanding of older citizens' perceived ability to adopt m-health. The results show that the $\mathrm{m}$-health digital divide persists due to low m-health self-efficacy and low privacy self-efficacy i.e the ability to protect one's privacy whilst using m-health technology. While online health data seeking experience provides some comfort, many older adults believe they currently lack the skills to utilize m-health applications for the purpose of health management. This negatively impacts their intentions to adopt m-health, and over time is likely to deepen the digital divide. Therefore, attempts to increase such adoption must focus on increasing older adults' confidence in their perceived ability to adopt and in ensuring the necessary supports are available to older adults post-adoption.

Third, to answer calls to explore the privacy concerns and adoption intentions of older citizens (Li et al., 2014; Kordzadeh et al., 2016), the study applies a multidimensional measure of concern and utilizes protection motivation theory to explore individuals' willingness to adopt based on the competing influences of threat and coping appraisals. The findings show that this digital divide is widened by older adults who despite having the ability to adopt, nonetheless abstain or adopt selectively. Many older adults were willing to use fitness and diet applications, but not applications for managing health conditions such as diabetes. This is problematic as the incidence of chronic illness increases with age, and self-management of such conditions would reduce the burden on health services (PWC, 2013). In line with PMT, the quantitative and qualitative findings confirm that HIPC strongly deter older citizens from m-health usage and reduces their willingness to disclose sensitive health data. This is consistent with $\mathrm{Li}$ et al. (2016), and extends our knowledge on the inhibiting role of privacy concerns on mhealth adoption among an older adult population. Older adults express high concerns especially across the dimensions of unauthorized secondary use, improper access, control, and awareness. In line with Conger et al. (2013), individuals desire control over their personal data but currently lack control particularly in the context of 
emerging technologies where sensitive data is requested, the flow of this information is unknown, and the risks unidentifiable (Keith et al., 2015). This highlights the need to communicate effectively with older adults to appease specific privacy concerns.

Finally, the study makes a methodological contribution by departing from the legacy of single-method quantitative privacy studies and answers calls for mixed methods research (Venkatesh et al., 2013) to provide rich insights into the health privacy concerns of an underexamined group. Moreover, as the first comparative study on older adults' health privacy concerns, it simultaneously answers calls for privacy studies in Northern Europe (Bélanger and Crossler, 2011), and cross-national privacy studies (Martin and Murphy, 2017). The holistic two-staged approach enabled detailed insights into the reasons underlying HIPC, the influence of HIPC on adoption, and differences within the older cohort. These insights could not have been attained solely through quantitative methods. The study highlights that individuals aged over 50 in this study, despite some differences in self-efficacy and risk beliefs, possess similarities in that they strongly desire health privacy and withhold sensitive data or abstain from m-health to protect this privacy. Thus, we can contend that $\mathrm{m}$-health digital divide is underpinned by low self-efficacy levels and further bolstered by high desire for privacy, low trust, and a perceived inability to utilize m-health while maintaining control over privacy.

\section{Practical Implications}

Leveraging the integrated findings, two important practical recommendations are made to address the needs and concerns of older adults and narrow the digital divide. Firstly, self-efficacy can be addressed through provision of educational programmes delivered through community centres or universities, to which health professionals can direct patients. Our qualitative data highlighted the importance of ensuring the necessary supports are available to older adults post-adoption. Secondly, the risk beliefs older adults associate with $\mathrm{m}$-health points to the need for vendors to engage in trust building and risk appeasing interventions. Health professionals are trusted influencers and the first point of communication with the patient. Vendors should therefore consider provision of information flyers to health professionals, which provide assurances regarding security, data storage conditions, the privacy of information, and citizens' ability to control privacy settings. Such information will reduce risk beliefs whilst simultaneously increasing the perception of control over health data.

\section{Limitations}

The limitations within the study must be acknowledged. The measurement of adoption intentions instead of behaviors is a limitation, however this approach was necessitated 
by the nascence of m-health (Hsieh, 2015), resistance among older adults (PEW, 2013), and the focus on m-health in a broad sense. While we cannot be certain the intentions expressed are fully representative of behavior, the exploration of intentions quantitatively and qualitatively provides a deeper understanding of the HIPC-Intention relationship. Future research should explore adoption behaviors where possible, and could focus on m-health applications collecting sensitive data to explore disclosure behaviors and privacy-protective behaviors. It is hoped that this study provides a starting point for such research. The sample did not include many individuals without any Internet experience $(n=4)$. Whilst it may be difficult to access this group, they might vary both in terms of their perceived ability to adopt and willingness to adopt.

\section{Future Research Directions}

The integrated findings illustrate many interesting avenues for research. Self-efficacy can be derived from four sources of experience; mastery, observational, social persuasion, and psychology (Bandura, 1986). Research which seeks to determine the effectiveness of different interventions for fostering older adults' $m$-health self-efficacy can provide important theoretical and practical insights. There is also a need for research which examines the role of trust in $\mathrm{m}$-health in a comprehensive manner including propensity to trust, trust beliefs regarding different organizations, and trust behaviors. In line with PMT, threat and coping appraisals and their interdependencies could be further examined to investigate the efficacy of efforts to build trust, reduce risk beliefs, and address specific and broad privacy concerns. With regards to older individuals' ability and willingness to adopt, there is a need to develop educational solutions to build privacy knowledge and foster privacy self-efficacy.

Many gaps persist in the broader privacy literature including organizational and societal research (Bélanger and $\mathrm{Xu}, 2015)$. While, this study does not adopt an organizational or societal approach, older citizens are an important and often marginalized group within society, who stand to benefit from m-health but resist adopting. Thus, this research is important on a societal level as it explores the specific needs of this cohort to provide recommendations for meeting their needs and narrowing the digital divide. To this end, we issue two calls. First, while acknowledging existing organizational privacy research (e.g. Greenaway, Chau and Crossler, 2015), we call for privacy researchers to explore organizational efforts to address the privacy concerns of specific groups such as older adults. Second, despite strong progress in social inclusion research, many challenges remain in narrowing the digital divide in technology-related opportunities and supports (Windeler and Riemenschneider, 2016). Thus, we extend 
recent calls for social inclusion IS research (Trauth, 2017) and call for privacy researchers and IS researchers in a broader sense to consider the intersectionality between crucial issues such as privacy and technology adoption, and important individual variables popularized in the social inclusion literature such as age, gender, ethnicity, and sexual orientation.

\section{Conclusion}

The m-health digital divide is deepening due to older individuals' inability to adopt, and unwillingness to utilize $\mathrm{m}$-health to manage sensitive conditions. This study highlights the need to educate this group to ensure they are capable of adopting, and to improve their privacy literacy so that they can make informed adoption decisions which consider the benefits of m-health and the associated privacy implications. In addition to its contribution to the body of knowledge, it is hoped that this study will benefit policy makers, and those interested in improving m-health adoption across generations.

\section{Acknowledgement}

This material is based upon works supported by Dublin City University under the Daniel O’Hare Research Scholarship scheme.

\section{References}

Agarwal, R., Gao, G., DesRoches, C. and Jha, A.K. 2010. The Digital Transformation of Healthcare: Current Status and the Road Ahead. Information Systems Research, 21(4), pp. 796-809.

Angst, C.M. and Agarwal, R. 2009. Adoption of electronic health records in the presence of privacy concerns: The elaboration likelihood model and individual persuasion. MIS Quarterly, 33(2), pp. 339-370.

Bandura, A. 1977. Self-efficacy: toward a unifying theory of behavioral change. Psychological Review, 84(2), pp. 191-215.

Bandura, A. 1986. Social foundations of thought and action: A social cognitive theory, Englewood Cliffs, NJ: Prentice-Hall, Inc.

Bansal, G., Zahedi, F.M. and Gefen, D. 2010. The impact of personal dispositions on information sensitivity, privacy concern and trust in disclosing health information online. Decision Support Systems, 49(2), pp. 138-150.

Bélanger, F. and Crossler, R.E. 2011. Privacy in the Digital Age: A review of Information Privacy Research in Information Systems. MIS Quarterly, 35(4), pp. $1017-41$.

Bélanger, F. and Xu, H. 2015. The role of information systems research in shaping the future of information privacy. Information Systems Journal, 25(6), pp.573-578. 
Bidmon, S., Terlutter, R. and Röttl, J. 2014. What explains usage of mobile physicianrating apps? Results from a web-based questionnaire. Journal of Medical Internet Research, 16(6), pp. e148.

Clarke, R. 1999. Internet Privacy Concerns Confirm the Case for Intervention. Communications of the ACM, 42(2), pp. 60-67.

Compeau, D. and Higgins, C.A. 1995. Application of social cognitive theory to training for computer skills. Information Systems Research, 6(2), pp. 118-143.

Connelly, K.H., Faber, A.M., Rogers, Y., Siek, K.A. and Toscos, T. 2006. Mobile applications that empower people to monitor their personal health. $e$ \& $i$ Elektrotechnik und Informationstechnik, 123(4), pp.124-128.

Conger, S., Pratt, J. H., and Loch, K. D. 2013. Personal information privacy and emerging technologies. Information Systems Journal, 23(5), pp. 401-417.

Creswell, J.W. and Plano Clark, V. 2007. Designing and Conducting Mixed Methods Research, Thousand Oaks, CA: Sage

Central Statistics Office (CSO). 2015. Information Society Statistics - Households. Available:

http://www.cso.ie/en/releasesandpublications/er/isshh/informationsocietystatisticshouseholds2015/

Central Statistics Office (CSO). 2016. Information Society Statistics - Households. Available:

http://www.cso.ie/en/releasesandpublications/er/isshh/informationsocietystatisticshouseholds2016/

Crossler, R.E., and Bélanger, F. 2017.The Mobile Privacy-Security Knowledge Gap Model: Understanding Behaviors. In Proceedings of the 50th Hawaii International Conference on System Sciences.

Cummings, E., Chau, S. and Turner, P., 2009. Assessing a patient-centered e-health approach to chronic disease self-management. In Wilson, E. V. (ed), Patient-centered e-health, pp.168-185, IGI Global; Hershey PA.

Davis, F.D., Bagozzi, R.P. and Warshaw, P.R. 1989. User Acceptance of Computer Technology: A Comparison of Two Theoretical Models. Management Science, 35(8), pp. 982-1003.

Dinev, T., Albano, V., Xu, H., D'Atroi, A. and Hart, P. 2016. Individuals' Attitudes Towards Electronic Health Records: A Privacy Calculus Perspective. IN: Gupta et al. (eds.) Advances in Healthcare Informatics and Analytics, Annals of Information Systems 19, Switzerland: Springer Publishing pp. 19-50.

Dinev, T., Xu, H., Smith, J.H. and Hart, P. 2012. Information privacy and correlates: an empirical attempt to bridge and distinguish privacy-related concepts. European Journal of Information Systems, 22(3), pp. 295-316

Eng, D.S. and Lee, J.M. 2013. The promise and peril of mobile health applications for diabetes and endocrinology. Pediatric diabetes, 14(4), pp. 231-8.

EIR. 2015. EIR Connected Living Survey. Available: http://banda.ie/wpcontent/uploads/FINAL-E00054329-EIRCUS-eir-Connected-Living-Survey.pdf 
Fichman, R.G., Kohli, R. and Krishnan, R. 2011. The role of information systems in healthcare: Current research and future trends. Information Systems Research, 22(3), pp. 419-428.

Fischer, S.H., David, D., Crotty, B.H., Dierks, M. and Safran, C. 2014. Acceptance and use of health information technology by community-dwelling elders. International Journal of Medical Informatics, 83(9), pp. 624-635.

Fornell, C. and Larcker, D. F. 1981. Evaluating structural equation models with unobservable variables and measurement error. Journal of Marketing Research, pp. 3950 .

FTC. 2014. Consumer Generated and Controlled Health Data [Online]. Available from:https://www.ftc.gov/system/files/documents/public_events/195411/privacyserie s-healthdataagenda.pdf

Gaskin, J. 2012. Confirmatory Factor Analysis [Online]. Available from: http://statwiki.kolobkreations.com/index.php?title=Confirmatory_Factor_Analysis

Goldfarb, A., and Tucker, C. 2013. Why managing consumer privacy can be an opportunity. MIT Sloan Management Review, 54(3), p.10.

Gorman, M. 1999. Development and the rights of older people. In: Randel J, et al., Eds. The ageing and development report: poverty, independence and the world's older people. London, Earthscan Publications Ltd., pp. 3-21.

Greene, J. C., and Caracelli, V. J. 2003. Making Paradigmatic Sense of Mixed Methods Practice. In A. Handbook of Mixed Methods in Social \& Behavioral Research (Tashakkori, A., \& Teddlie, C. (Eds.)): pp. 91-110, Thousand Oaks, CA: Sage Publications.

Greenaway, K.E., Chan, Y.E. and Crossler, R.E., 2015. Company information privacy orientation: a conceptual framework. Information Systems Journal, 25(6), pp.579-606.

Guo, X., Sun, Y., Wang, N., Peng, Z. and Yan, Z. 2013. The dark side of elderly acceptance of preventive mobile health services in China. Electronic Markets, 23(1), pp. 49-61.

Hair, J.F., Black, W.C., Babin, B.J. and Anderson, R.E. 2010. Multivariate Data Analysis, A Global Perspective, New Jersey: Pearson Education.

Hong, W. and Thong, J. 2013. Internet Privacy Concerns: An Integrated Conceptualisation and four empirical studies. MIS Quarterly, 37(1), pp. 275-298.

Hsieh, P.J. 2015. Physicians' acceptance of electronic medical records exchange: An extension of the decomposed TPB model with institutional trust and perceived risk. International Journal of Medical Informatics, 84(1), pp.1-14.

Hwang, H.G., Han, H.E., Kuo, K.M. and Liu, C.F. 2012. The differing privacy concerns regarding exchanging electronic medical records of internet users in Taiwan. Journal of medical systems, 36(6), pp. 3783-3793.

Joinson, A., Reips, U.D., Buchanan, T. and Schofield, C.B.P. 2010. Privacy, Trust, and Self-Disclosure Online. Human-Computer Interaction, 25(1), pp. 1-24. 
Kehr, F., Kowatsch, T., Wentzel, D., and Fleisch, E. 2015. Blissfully Ignorant: The Effects of General Privacy Concerns, General Institutional Trust, and Affect in the Privacy Calculus, Information Systems Journal 25(6), pp. 607-635.

Keith, M.J., Babb, J.S., Lowry, P.B., Furner, C.P. and Abdullat, A., 2015. The role of mobile-computing self-efficacy in consumer information disclosure. Information Systems Journal, 25(6), pp.637-667.

Kemper, E.A., Stringfield, S. and Teddlie, C. 2003. Mixed Methods Sampling Strategies in Social Science Research. IN: Tashakkori, A. and Teddlie, C. (eds.) Handbook of Mixed Methods in Social \& Behavioral Research, Thousand Oaks, CA: Sage Publications, pp. 273-319.

Kim, J. and Park, H.A. 2012. Development of a health information technology acceptance model using consumers' health behavior intention. Journal of Medical Internet Research, 14(5), pp. e133.

Klein, R. 2007. Internet-Based Patient-Physician Electronic Communication Applications: Patient Acceptance and Trust. e-Service Journal, 5(2), pp. 27-52.

Kordzadeh, N., Warren, J. and Seifi, A. 2016. Antecedents of privacy calculus components in virtual health communities. International Journal of Information Management, 36, pp. 724-734.

Kvale, S. 1996. The interview situation. In: Interviews. An Introduction to Qualitative Research Interviewing, Kvale, S. (ed.) London: Sage, pp. 124-143.

Kvansy, L., and Trauth, E. M. 2002. The 'digital divide' at work and home: the discourse about power and underrepresented groups in the information society. In: Global and Organizational Discourse about Information Technology, Wynn, E., Myers, M. D. and Whitley, E. A. (eds), pp. 273-291.

Laric, M.V., Pitta, D.A. and Katsanis, L. P. 2009. Consumer Concerns for Healthcare Information Privacy: A comparison of US and Canadian Perspectives. Research in Healthcare Financial Management, 12(1), pp. 93-111.

Li, T. and Slee, T. 2014. The effects of information privacy concerns on digitizing personal health records. Journal of the Association for Information Science and Technology, 65(8), pp. 1541-1554.

Li, Y. 2011. Empirical studies on online information privacy concerns: Literature review and an integrative framework. Communications of the Association for Information Systems, 28, pp. 453-496.

Li, H., Gupta, A., Zhang, J. and Sarathy, R., 2014. Examining the decision to use standalone personal health record systems as a trust-enabled fair social contract. Decision Support Systems, 57, pp.376-386.

Li, H., Wu, J., Gao, Y. and Shi, Y. 2016. Examining individuals' adoption of healthcare wearable devices: An empirical study from privacy calculus perspective. International Journal of Medical Informatics, 88, pp. 8-17

Li, Y. 2012. Theories in online information privacy research: A critical review and an integrated framework. Decision Support Systems, 54(1), pp. 471-481. 
Lim, S., Xue, L., Yen, C.C., Chang, L., Chan, H.C., Tai, B.C. and Choolani, M. 2011. A study on Singaporean women's acceptance of using mobile phones to seek health information. International Journal of Medical Informatics, 80(12), pp. e189-202.

Lincoln, Y.S. and Guba, E.G. 1985. Naturalistic Inquiry, Newbury Park, CA: Sage.

MacKenzie, S.B., Podsakoff, P.M. and Podsakoff, N.P. 2011. Construct measurement and validation procedures in MIS and behavioral research: Integrating new and existing techniques. MIS Quarterly, 35(2), pp. 293-334.

Malhotra, N.K., Kim, S.S. and Agarwal, J. 2004. Internet Users' Information Privacy Concerns (IUIPC): The Construct, the Scale and a Causal Model. Information Systems Research, 15(4), pp. 336- 355.

Martin, K.D. and Murphy, P.E., 2017. The role of data privacy in marketing. Journal of the Academy of Marketing Science, pp.1-21.

McKnight, D.H., Choudhury, V. and Kacmar, C. 2002. Developing and validating trust measures for e-commerce: An integrative typology. Information Systems Research, 13(3), pp. 334-359.

Morgan, A. J., and Trauth, E. M. 2013. Socio-economic influences on health information searching in the USA: the case of diabetes. Information Technology \& People, 26, pp. 324-346.

Mosa, A.S.M., Yoo, I. and Sheets, L. 2012. A systematic review of healthcare applications for smartphones. BMC Medical Informatics and Decision Making, 12(67), pp. 1-31.

Niehaves, B., and R. Plattfaut, R. 2013. Internet adoption by the elderly: employing IS technology acceptance theories for understanding the age-related digital divide. European Journal of Information Systems, 23(6), pp. 708-726.

Nissenbaum, H. 2010. Privacy in Context: Technology, Policy, and the Integrity of Social Life. Stanford Law Books, Stanford, California.

Nolan, A. and Kenny, A. 2014. The Over 50s in a Changing Ireland: Economic Circumstances, Health and Well-Being. TILDA Wave Two Key Findings [Online]. Available from: http://tilda.tcd.ie/assets/pdf/Wave2-Key-Findings-Report.pdf.

O'Cathain, A., Murphy, E. and Nicholl, J., 2008. The quality of mixed methods studies in health services research. Journal of Health Services Research \& Policy, 13(2), pp. 92-98.

O'Cathain, A., Murphy, E. and Nicholl, J., 2010. Three techniques for integrating data in mixed methods studies. British Medical Journal: BMJ, 341, pp. 4587.

Or, C.K.L. and Karsh, B.T. 2009. A systematic review of patient acceptance of consumer health information technology. Journal of the American Medical Informatics Association: JAMIA 16(4), pp. 550-60.

Or, C.K.L., Karsh, B.T. Severtson, D.J., Burke, L.J., Brown, R.L. and Brennan, P.F. 2011. Factors affecting home care patients' acceptance of a web-based interactive selfmanagement technology. Journal of the American Medical Informatics Association: JAMIA, 18(1), pp. 51-9. 
Pew Research Center. 2013. Health Fact Sheet [Online]. Available from: http://www.pewinternet.org/fact-sheets/health-fact-sheet/ [Accessed on 11 $1^{\text {th }}$ August 2015].

Podsakoff, P.M., MacKenzie, S.B., Lee, J.Y. and Podsakoff, N.P. 2003. Common method biases in behavioral research: a critical review of the literature and recommended remedies. The Journal of Applied Psychology, 88(5), pp. 879-903.

Preacher, K. J., and Hayes, A. F. 2004. SPSS and SAS procedures for estimating indirect effects in simple mediation models. Behavior Research Methods, Instruments, \& Computers, 36, pp. 717-731.

PWC 2013. Socio-economic impact of m-health. An assessment report for the European Union, [Online]. Available from: http://www.gsma.com/connectedliving/wp-content/uploads/2013/06/Socioeconomic_impactof-m-health_EU_14062013V2.pdf.

Rai, A., Chen, L., Pye, J. and Baird, A. 2013. Understanding determinants of consumer mobile health usage intentions, assimilation, and channel preferences. Journal of Medical Internet Research, 15(8), pp. e149.

Raykov, T. 1997. Estimation of composite reliability for congeneric measures. Applied Psychological Measurement, 21(2), pp. 173-184.

Ritchie, J. and Spencer, L. 1994. Qualitative data analysis for applied policy research. IN: Bryman, A. and Burgess, R.G. (eds.) Analysing Qualitative Data, London: Routledge, pp. 173-194.

Rogers, R.W. 1975. A protection motivation theory of fear appeals and attitude change. Journal of Psychology, 91(1), pp. 93-114.

Shaw, N.T., Kulkarni, A. and Mador, R.L. 2011. Patients and Health Care Providers' Concerns about the Privacy of Electronic Health Records: A Review of the Literature. Electronic Journal of Health Informatics, 6(1), pp. 1-5.

Smith, H.J., Milberg, S.J. and Burke, S.J. 1996. Information privacy: Measuring individuals' concerns about organizational practices. MIS Quarterly, (20), pp. 167196.

Smith, H. J. Dinev, T. and Xu, H. 2011. Information Privacy Research: An Interdisciplinary Review. MIS Quarterly 35(4), pp. 989-1015.

Son, J.Y and Kim, S.S. 2008. Internet users' information privacy-protective responses: a taxonomy and a nomological model. MIS Quarterly, pp.503-529.

Sun, Y., Wang, N., Guo, X. and Peng, Z. 2013. Understanding the acceptance of mobile health services: a comparison and integration of alternative models. Journal of Electronic Commerce Research, 14(2), pp. 183.

Teddlie, C. and Tashakkori, A. 2009. Foundation of Mixed Methods Research: Integrating Quantitative and Qualitative Approaches in the Social and Behavioral Sciences. Thousand Oaks, CA: Sage Publications.

Trauth, E. 2017. A Research Agenda for Social Inclusion in Information Systems. ACM SIGMIS Database: the DATABASE for Advances in Information Systems, 48(2), pp.920. 
Venkatesh, V., Morris, M.G., Davis, G.B. and Davis, F.D. 2003. User Acceptance of Information Technology: Toward a Unified View. MIS Quarterly, 27(3), pp. 425-478.

Venkatesh, V., Brown, S.A. and Bala, H. 2013. Bridging the qualitative-quantitative divide: Guidelines for conducting mixed methods research in information systems. MIS Quarterly, 37, pp. 21-54.

Whittaker, R. 2012. Key Issues in Mobile Health and Implications for New Zealand. Healthcare and Informatics Review Online, 16(2), pp. 2-7.

WHO 2015. Definition of an older or elderly person [Online]. Available from: http://www.who.int/healthinfo/survey/ageingdefnolder/en/ [Accessed $1^{\text {st }}$ June 2015].

WHO, 2013. Proposed working definition of an older person in Africa for the MDS Project [Online] Available: http://www.who.int/healthinfo/survey/ageingdefnolder/en/

Wilson, V.E. and Lankton, N.L. 2004. Modeling Patients' Acceptance of Providerdelivered E- health. Journal of the American Medical Informatics Association, 11(4), pp. 241-249.

Windeler, J. B., and Riemenschneider, C.K. 2016. The influence of ethnicity on organizational commitment and merit pay of IT workers: the role of leader support. Information Systems Journal, 26(2), pp.157-190.

Wu, J. H., Wang, S.C. and Lin, L. M. 2007. Mobile computing acceptance factors in the healthcare industry: a structural equation model. International Journal of Medical Informatics, 76(1), pp. 66-77.

Xu, H., and Bélanger, F. 2013. Information systems journal special issue on: Reframing privacy in a networked world. Information Systems Journal, 23(4), pp.371-375.

Xu, H., Dinev, T., Smith, J. and Hart, P. 2011. Information Privacy Concerns: Linking Individual Perceptions with Institutional Privacy Assurances. Journal of the Association for Information Systems, 12(12), pp. 798-824.

Zhao, X., Lynch, J. G. and Chen, Q. 2010. Reconsidering Baron and Kenny: Myths and truths about mediation analysis. Journal of Consumer Research, 37(2), pp. 197206. 


\section{Appendix 1. Survey Items (minus dropped items)}

\section{Health Information Seeking Behavior INF (3 items) (Kim and Park 2012)}

INF1: I search online for information related to disease diagnosis and treatment INF2: I search online for information related to health management (exercise, diet, mental health, etc.)

INF3: I search online for health information for education, research or learning purposes

\section{HIPC (19 items) (Hong and Thong 2013) \\ Collection}

COLL1: It usually bothers me when health care entities ask me for personal health information.

COLL2: It bothers me to give my personal health information to so many health care entities

COLL3: When health care entities ask me for personal health information, I sometimes think twice before providing it

COLL4: I'm concerned that health care entities are collecting too much personal health information about me

Secondary Use

SEC1: I am concerned that when I give personal health information to a healthcare entity for some reason, that they might use the information for other reasons

SEC2: I am concerned that health care entities would sell my health personal health information in their computer databases to other health care entities or non-health related organizations

SEC3: I am concerned that health care entities would share my personal health information with other health care entities without my authorisation

Improper Access

ACC1: I am concerned that health care entities do not devote enough time and effort to preventing unauthorised access to my personal health information

ACC2: I am concerned that health care entities' databases that contain my personal health information are not protected from unauthorised access

ACC3: I am concerned that health care entities do not take enough steps to make sure that unauthorised people cannot access my personal health information in their computers

\section{Errors}

ERR1: I am concerned that health care entities do not devote enough time and effort to verifying the accuracy of my personal information in their databases

ERR2: I am concerned that health care entities do not have adequate procedures to correct errors in my personal health information

ERR3: I am concerned that health care entities do not take enough steps to make sure that my personal health information in their files is accurate

Control

CON1: It usually bothers me when I do not have control of personal health information that I provide to health care entities

CON2: I am concerned when control is lost or unwillingly reduced as a result of providing health care entities with my personal health information

CON3: It usually bothers me when I do not have control or autonomy over decisions about how my personal health information is used, and shared by health care entities Awareness

AWR1: It usually bothers me when I am not aware or knowledgeable about how my personal health information will be used by health care entities

AWR2: It is very important to me that I am aware and knowledgeable about how my personal health information will be used by health care entities

AWR3: It usually bothers me when health care entities seeking my health information do not disclose the way the data are processed and used 
Intention INT (3 items) (Venkatesh et al. 2013)

INT1: I intend to use m-health technologies

INT2: I plan to use m-health technologies

INT3: I predict I will use m-health technologies

\section{Trust beliefs TRT (4 items) (Hong and Thong, 2013; Li et al. 2014)}

TRT1: I know technology vendors are always honest when it comes to using my health information

TRT2: I know technology vendors care about customers

TRT3: I know technology vendors are not opportunistic when using my health information

TRT4: I know technology vendors are predictable and consistent with regards to using my health information

TRT5: I trust that technology vendors keep my best interests in mind when dealing with my health information

\section{Risk Perceptions RSK (4 items) (Hong and Thong, 2013; Li et al. 2014)}

RSK1: It would be risky to disclose my personal health information to technology vendors

RSK2: There would be high potential for loss associated with disclosing my personal health information to technology vendors

RSK3: There would be too much uncertainty associated with giving my personal health information to technology vendors

RSK4: Providing technology vendors with my personal health information would involve many unexpected problems

\section{M-health Self-efficacy MHSE (3 items) (Kim and Park 2012)}

MHSE1: I could use health technologies to manage my health, if I had used a similar technology before

MHSE2: I could use health technologies to manage my health, if someone showed me how to

MHSE3: I could use health technologies to manage my health, if I had time to try them out 
Appendix 2. Descriptive Statistics, Older Cohort

\begin{tabular}{|c|c|c|c|c|}
\hline Variable & First Order & Item & $\begin{array}{l}\text { Mean } \\
50+\end{array}$ & $\begin{array}{l}\text { Std.Dev } \\
50+\end{array}$ \\
\hline \multirow[t]{5}{*}{ INT } & & & 3.09 & 0.99 \\
\hline & & INT1 & 3.18 & 1.08 \\
\hline & & INT2 & 3.15 & 1.06 \\
\hline & & INT3 & 3.28 & 1.09 \\
\hline & & & 2.95 & 0.88 \\
\hline \multirow[t]{5}{*}{ TRT } & & TRT1 & 2.47 & 0.80 \\
\hline & & TRT2 & 2.62 & 0.90 \\
\hline & & TRT3 & 2.48 & 0.80 \\
\hline & & TRT4 & 2.64 & 0.81 \\
\hline & & TRT5 & 2.57 & 0.95 \\
\hline \multirow[t]{5}{*}{ RISK } & & & 3.83 & 0.95 \\
\hline & & RSK1 & 3.74 & 0.93 \\
\hline & & RSK2 & 3.54 & 0.93 \\
\hline & & RSK3 & 3.66 & 0.98 \\
\hline & & RSK4 & 3.51 & 0.96 \\
\hline \multirow[t]{30}{*}{ HIPC } & & & 3.44 & 0.77 \\
\hline & COLL & & 3.26 & 0.79 \\
\hline & & COLL1 & 3.12 & 1.18 \\
\hline & & COLL2 & 3.38 & 1.26 \\
\hline & & COLL3 & 3.47 & 1.15 \\
\hline & & COLL4 & 3.54 & 1.13 \\
\hline & SECU & & 3.41 & 0.79 \\
\hline & & SECU1 & 3.45 & 1.11 \\
\hline & & SECU2 & 3.58 & 1.21 \\
\hline & & SECU3 & 3.95 & 1.05 \\
\hline & ACC & () & 3.53 & 0.85 \\
\hline & & ACC1 & 3.87 & 1.11 \\
\hline & & ACC2 & 3.69 & 1.13 \\
\hline & & ACC3 & 3.82 & 1.13 \\
\hline & & & 3.64 & 0.82 \\
\hline & & ERR1 & 3.80 & 1.10 \\
\hline & & ERR2 & 3.80 & 1.11 \\
\hline & & ERR3 & 3.79 & 1.03 \\
\hline & & & 3.69 & 0.75 \\
\hline & & CON1 & 3.78 & 1.04 \\
\hline & & CON2 & 4.06 & 0.97 \\
\hline & & CON3 & 3.89 & 0.99 \\
\hline & AWA & & 3.78 & 0.77 \\
\hline & & AWA1 & 3.90 & 1.04 \\
\hline & & AWA2 & 4.05 & 0.92 \\
\hline & & AWA3 & 4.33 & 0.81 \\
\hline & & & 2.13 & 0.92 \\
\hline & & INF1 & 2.17 & 1.07 \\
\hline & & INF2 & 2.15 & 1.05 \\
\hline & & INF3 & 2.15 & 1.28 \\
\hline \multirow[t]{4}{*}{ MHSE } & & & 4.60 & 0.95 \\
\hline & & MHSE1 & 3.61 & 0.89 \\
\hline & & MHSE2 & 3.90 & 0.82 \\
\hline & & MHSE3 & 3.73 & 0.89 \\
\hline \multirow[t]{3}{*}{ HN } & & & 3.21 & 1.03 \\
\hline & & HN1 & 2.82 & 1.10 \\
\hline & & HN2 & 2.41 & 0.80 \\
\hline
\end{tabular}


Appendix 3. CFA Factor Loading Scores for All Items

\begin{tabular}{|c|c|c|c|c|c|c|c|c|c|c|c|}
\hline $\begin{array}{l}\text { Latent } \\
\text { Variable }\end{array}$ & $\begin{array}{l}\text { First } \\
\text { Order }\end{array}$ & Item & $\begin{array}{l}\text { INT } \\
\alpha=.96\end{array}$ & $\begin{array}{l}\text { TRT } \\
\alpha=.87\end{array}$ & $\begin{array}{l}\text { RSK } \\
\alpha=.92\end{array}$ & $\begin{array}{l}\text { HIPC } \\
\alpha=.97\end{array}$ & $\begin{array}{l}\text { INF } \\
\alpha=.81\end{array}$ & $\begin{array}{l}\text { MHSE } \\
\alpha=.85\end{array}$ & $\begin{array}{l}H N \\
\alpha=.77\end{array}$ & CR & AVE \\
\hline \multirow[t]{3}{*}{ INT } & & INT1 & .94 & & & & & & & .96 & .88 \\
\hline & & INT2 & .97 & & & & & & & & \\
\hline & & INT3 & .90 & & & & & & & & \\
\hline \multirow[t]{5}{*}{ TRT } & & TRT1 & & .77 & & & & & & .90 & .57 \\
\hline & & TRT2 & & .72 & & & & & & & \\
\hline & & TRT3 & & .76 & & & & & & & \\
\hline & & TRT4 & & .71 & & & & & & & \\
\hline & & TRT5 & & .82 & & & & & & & \\
\hline \multirow[t]{4}{*}{ RISK } & & RSK1 & & & .87 & & & & & .93 & .75 \\
\hline & & RSK2 & & & .87 & & & & & & \\
\hline & & RSK3 & & & .88 & & & & & & \\
\hline & & RSK4 & & & .86 & & & & & & \\
\hline \multirow[t]{19}{*}{ HIPC } & & & & & & & & & & .98 & .89 \\
\hline & COLL: & COLL1 & & & & .78 & & & & .89 & .67 \\
\hline & .962 & COLL2 & & & & .82 & & & & & \\
\hline & & COLL3 & & & & .89 & & & & & \\
\hline & & COLL4 & & & & .83 & 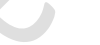 & & & & \\
\hline & SECU: & SECU1 & & & & .82 & & & & .89 & .72 \\
\hline & .962 & SECU2 & & & & .87 & & & & & \\
\hline & & SECU3 & & & & .91 & & & & & \\
\hline & ACC: & ACC1 & & & & .90 & & & & .91 & .77 \\
\hline & .947 & ACC2 & & & & .88 & & & & & \\
\hline & & ACC 3 & & & & .90 & & & & & \\
\hline & ERR: & ERR1 & & & & .89 & & & & .88 & .71 \\
\hline & .952 & ERR2 & & & & .84 & & & & & \\
\hline & & ERR3 & & & & .85 & & & & & \\
\hline & CON: & CON1 & & ) & & .83 & & & & .88 & .72 \\
\hline & .940 & CON2 & & & & .88 & & & & & \\
\hline & & CON3 & & & & .86 & & & & & \\
\hline & AWA: & AWA1 & & & & .93 & & & & .92 & .79 \\
\hline & .912 & AWA2 & & & & .89 & & & & & \\
\hline \multirow[t]{3}{*}{ INF } & & $\begin{array}{l}\text { AVAB } \\
\text { INF1 }\end{array}$ & & & & & .73 & & & .82 & .60 \\
\hline & & INF2 & & & & & .86 & & & & \\
\hline & & INF3 & & & & & .72 & & & & \\
\hline \multirow{3}{*}{ MHSE } & & MHSE1 & & & & & & .72 & & .85 & .70 \\
\hline & & MHSE2 & & & & & & .85 & & & \\
\hline & & MHSE3 & & & & & & .88 & & & \\
\hline \multirow[t]{2}{*}{$\mathrm{HN}$} & & $\mathrm{HN} 1$ & & & & & & & .85 & .82 & .61 \\
\hline & & HN2 & & & & & & & .91 & & \\
\hline
\end{tabular}

Note: CR and AVE for COLL, SECU, ACC, ERR, CON and AWA were tested by removing by second order HIPC factor and modeling as six first order factors. Despite evidencing strong composite reliability scores and AVE, the factors were not discriminately valid. Thus, further support for the proposed sector order factor is provided. 
Appendix 4. Nationality and Age based Comparisons

\begin{tabular}{|c|c|c|}
\hline Construct & Role of Nationality & Role of Age \\
\hline $\begin{array}{l}\text { Information } \\
\text { Seeking }\end{array}$ & $\begin{array}{l}\text { There were some expected } \\
\text { differences in the reliable sources } \\
\text { used e.g. Mayo Clinic in US vs. } \\
\text { NHS in Ireland. Furthermore, Irish } \\
\text { interviewees were more likely to } \\
\text { search based on a doctor's } \\
\text { recommendation. }\end{array}$ & $\begin{array}{l}\text { No age differences in willingness to } \\
\text { search online. However, only a small } \\
\text { number of interviewees, all of whom } \\
\text { were under } 60 \text { were willing to seek } \\
\text { information related to health } \\
\text { conditions. }\end{array}$ \\
\hline $\begin{array}{l}\text { M-health } \\
\text { Self-efficacy }\end{array}$ & $\begin{array}{l}\text { All US interviewees believed they } \\
\text { could use m-health with some } \\
\text { training, whereas in Ireland some } \\
\text { interviewees stated training might } \\
\text { not be sufficient to ensure they } \\
\text { were confident. Additional issues } \\
\text { around trust and benefits were } \\
\text { mentioned in both countries. }\end{array}$ & $\begin{array}{l}\text { There were slight differences in } \\
\text { perceived ability to use m-health. As } \\
\text { expected those still in employment } \\
\text { believed training would improve their } \\
\text { confidence. However, willingness to } \\
\text { use m-health regardless of skill level } \\
\text { did not vary across interviewees of } \\
\text { differing ages. }\end{array}$ \\
\hline $\begin{array}{l}\text { Risk } \\
\text { Perceptions }\end{array}$ & $\begin{array}{l}\text { There were no evident differences } \\
\text { in the level of risk perceptions. } \\
\text { However, some US interviewees } \\
\text { discussed negative outcomes as } \\
\text { unavoidable, whereas Irish } \\
\text { interviewees felt that withholding } \\
\text { data could protect against } \\
\text { negative outcomes. }\end{array}$ & $\begin{array}{l}\text { An awareness gap emerged with } \\
\text { younger interviewees }(50-60) \\
\text { demonstrating awareness of the } \\
\text { many possible risks of potential } \\
\text { misuse or unauthorized access, } \\
\text { whereas older interviewees' risk } \\
\text { beliefs were formed from a lack of } \\
\text { awareness and an innate fear of the } \\
\text { unknown. }\end{array}$ \\
\hline Trus & $\begin{array}{l}\text { There were no evident disparities } \\
\text { in trust levels across both } \\
\text { countries. However, many Irish } \\
\text { interviewees lacked trust in the } \\
\text { integrity of technology companies } \\
\text { in a general sense, whereas US } \\
\text { interviewees questioned the } \\
\text { intentions of health technology } \\
\text { vendors specifically. }\end{array}$ & $\begin{array}{l}\text { There was a disparity among } \\
\text { interviewees in terms of how trust } \\
\text { could be built. For the older } \\
\text { interviewees among the cohort, } \\
\text { technology companies could not be } \\
\text { trusted. Younger interviewees noted } \\
\text { they would likely trust the intentions } \\
\text { of established players in the health } \\
\text { industry. }\end{array}$ \\
\hline HIP & $\begin{array}{l}\text { All Irish interviewees expressed a } \\
\text { strong desire for privacy in a } \\
\text { broad sense, whereas the } \\
\text { concerns of US interviewees were } \\
\text { rooted in the fact they felt their } \\
\text { health privacy was diluted. } \\
\text { Interviewees across both } \\
\text { countries lacked an awareness of } \\
\text { how their health data was } \\
\text { currently used or their own } \\
\text { disclosure behaviors, often } \\
\text { assuming privacy. This lack of } \\
\text { awareness was more evident } \\
\text { among the Irish sample. }\end{array}$ & $\begin{array}{l}\text { All interviewees expressed concerns } \\
\text { regarding potential misuse and } \\
\text { unauthorized access, but younger } \\
\text { interviewees were more likely to (1) } \\
\text { believe this could happen and (2) feel } \\
\text { comforted by explicit promises to } \\
\text { protect privacy. Older interviewees } \\
\text { believed abstaining from use of m- } \\
\text { health for tracking health conditions } \\
\text { was the only way of ensuring privacy. }\end{array}$ \\
\hline Intention & $\begin{array}{l}\text { For Irish interviewees, reliable } \\
\text { recommended solutions, } \\
\text { education, and prove of } \\
\text { trustworthiness were important } \\
\text { caveats to adoption, whereas in } \\
\text { the US, education and control } \\
\text { were highly important. }\end{array}$ & $\begin{array}{l}\text { Irrespective of age, many } \\
\text { interviewees were unwilling to use m- } \\
\text { health for sensitive conditions. This } \\
\text { unwillingness was stronger among } \\
\text { individuals still in employment. }\end{array}$ \\
\hline
\end{tabular}

